\title{
Separating Prescription From Dispensation Medicines: Economic Effect Estimation in Japan
}

\author{
Masayuki Yokoi ${ }^{1,2}$ \& Takao Tashiro ${ }^{1}$ \\ ${ }^{1}$ The School of Graduate Studies, The Open University of Japan, Chiba, Japan \\ 2 Pascal Pharmacy, Shiga, Japan \\ Correspondence: Masayuki Yokoi, Pascal Pharmacy, Oji 1-11-16, Kusatsu, Shiga Prefecture, 525-0032, Japan. \\ Tel: 81-077-562-9354. E-mail: pascal@nike.eonet.ne.jp
}

\author{
Received: February 25, 2018 Accepted: April 3, 2018 Online Published: April 11, 2018 \\ doi:10.5539/gjhs.v10n5p88 \\ URL: https://doi.org/10.5539/gjhs.v10n5p88
}

\begin{abstract}
This study examined the effects of the separation between dispensing and prescribing medicines by pharmacists in pharmacies and doctors in medical institutions, respectively (separation system). The methodology avails public national data. The participation of Japanese medical institutions to the separation system was optional according to the legal system. Consequently, its spreading rate for each administrative district is highly variable, allowing us to study its correlation with various medication costs and other factors, such as the generic medicine replacement ratio, proportion of elderly, and number of doctors per 100000 individuals as independent variables. These four factors are known to be influential in medical compensation. We used regression analysis by the weighted least square method, with dependent variables being costs of daily medicines, specifically, total, internal, one-shot, external, and injection medicines; medical devices, brand-name medicines, generic medicines, and number of prescribed medicines; as well as technical fees. The analysis focused on whether the extent of the separation system reduces costs such as those for medicines, medical devices, technical fees, or number of prescribed medicines. The partial regression coefficient of the spreading rate of the separation system was found to have negative relationships with all daily costs and number of prescribed medicines, as well as the technical fee, except for external medicines, for which most of the market is represented by light analgesics (taken by patients as needed). The necessity of separating prescribing and dispensing is thus low because of the low information asymmetry between doctors and patients. The results revealed that promoting the separation system reduced medication costs, because it normalized the medication market for daily necessities by compensating information asymmetry. Furthermore, the separation system reduced excesses in prescribing medicines.
\end{abstract}

Keywords: prescription, dispensation, medicine, separation system, economic effect

\section{Introduction}

In the late 20th century, Japan introduced separation between prescription and dispensation medicines by doctors in medical institutions and pharmacists in pharmacies, respectively (hereafter, separation system). When the economic evaluations of clinical pharmacy interventions were studied, methodological problems appeared, including the absence of a control group, as the listing of public medicine prices undergoes a revision once every two years in addition to four revisions a year, the changes being too frequent to compare each fiscal year data. As a result, reports differed on whether the separation system has been effective in reducing medication costs since the 1960s. Moreover, the economic effectiveness of the separation system has not been quantitatively investigated in detail, as it is difficult to accurately compare the objects under study. Particularly, it is impossible to undertake a double-blind test of the separation system, as experience content, by its nature, must be known by doctors, patients, and pharmacists. Despite these difficulties, Japan's separation system proliferated in the 1990s and, in 2016, was present in over $70 \%$ of all healthcare facilities in Japan according to the Japan Pharmaceutical Association (2016).

Yokoi and Tashiro (2014) reported the relationship of the separation system with medicine costs in Japan. Multiple regression analysis revealed that the spreading rate of the system and that of replacing brand name medicines with generic ones had a significant negative partial correlation with daily internal medicine costs. This finding indicated the separation system might contribute to curtailing daily drug expenses in Japan. Although the separation system is mutual between prescribing doctors and pharmacists, the few national-level reports that promote the separation system showed a reduced number of prescribed medicines. However, there are several reports that investigate the 
effectiveness of interventions by community pharmacists. For example, Elliott, Putman, Davis, and Annemans (2014) reported the effectiveness of reducing polypharmacy by intervention of pharmacists through a systematic review and Touchette et al. (2014) discussed the economic evaluation of clinical pharmacy services. Akinbosoye, Taitel, Grana, Hill, and Wade (2016) reported the impact of a multifaceted set of medication management interventions offered by a community pharmacy. As a result, a multifaceted set of medication management interventions offered by a community pharmacy were associated with the patients in a commercial population having significantly higher medication adherence and lower healthcare utilization and costs. Although these reports designated that the community pharmacy contributed to medical cost reduction, they do not analyze national level data.

\section{Research Objective}

Previous studies revealed the financial efficiency of the separation system by undertaking multiple linear regression analysis for Japanese prefecture-level data (Yokoi \& Tashiro, 2016). Although prescription numbers varied by prefecture, this study did not considered prescription numbers.

Therefore, we specifically used weighted least square (WLS) regression, with dependent variables being costs of daily medicines, specifically, total, internal, one-shot, external, and injection medicines, medical devices, brand-name medicines, generic medicines, number of prescribed medicines, as well as technical fee. The analysis focused on whether the spreading of the separation system was the determinant for reducing costs such as for medicines, medical devices, technical fee, number of prescribed medicines. Furthermore, we analyze whether the separation system influenced more brand-name or generic medicines.

\section{Methodology}

All Japanese individuals must be associated to a specific public health insurance system under Japanese law, with exceptions applied to welfare for livelihood protection because their financial resources are covered from tax, not public health insurance. Although covered by tax, their insurance healthcare data are reported in the national health insurance data. Therefore, we can study all Japanese medical costs by availing national health insurance system data.

Although there are the components of self-paying and public insurance costs in the amount due when Japanese health insurance is applied at the medical institution or community pharmacy, national health insurance system data indicate the price including both.

We performed multiple linear regression analysis by WLS, using daily medicine costs for internal use or other medicine costs and fees per prescription as dependent variable. As independent variables, we used the expanding rate of the separation system, ratio of generic medicines replaced with brand-name ones, proportion of individuals 75 or older, and number of doctors per 100000 individuals. Weights were determined by examining the prescription sheets submitted to the pharmacies in each prefecture, from national health insurance data. We hypothesize these variables considerably correlate with daily medicine costs. The medicine costs for a prescription are influenced by numerous factors. For determining the net influence of the separation system, other factors besides the separation system must be canceled as well as possible. This method can thus cancel the influence of other factors excepted from the separation system.

We studied the correlation between medication costs per prescription and medical expense determinants by analyzing objective nationwide prefecture-level data derived from three sources - the Japanese Statistics Bureau of the Ministry of Internal Affairs and Communications (JSB); Ministry of Health, Labour, and Welfare Insurance Bureau Security Research Division (JMHLW); and Japan Pharmaceutical Association (JPA), a nonprofit public service corporation.

\subsection{Dependent Variable}

\subsubsection{Definitions}

Total medicine cost included all medicines on a prescription, whether internal, external, or injection medicines, or medical devices. Internal medicines are oral medicines and usage doses are mentioned on the prescription. One-shot administration medicines are a type of internal medicines characteristic to Japanese prescriptions that are to be taken by self-judgement when patients feel subjective symptoms and their usage dose is not mentioned on the prescription. External medicines are patches, nasal drops, suppositories, enemas, eye drops, ear-drops, and gargles. Injection medicines are only for outpatient use, such as, anticancer treatments, insulin, and hormones. Medical devices include injection needles and catheters for outpatient use. Furthermore, we also analyzed brand-name medicine costs, generic medicine costs, number of prescribed medicines, and technical fee for a prescription, as 
dependent variables. A technical fee is the cost paid to the pharmacy for dispensing medicines, excluding the total medicine cost of a prescription. In other words, it is type of commission and its price is legally determined by public insurance rules.

From the JMHLW (2016) website, we obtained data on average medicine costs and dosage days per prescription for each prefecture in 2016, using the same database as Yokoi and Tashiro (2016). Nationwide data on prescriptions use the insurance applications received by pharmacies for medical expenses, $99.4 \%$ of which are currently covered by medical insurance. The descriptive statistics of the dependent variable (per prescription) in the analysis of the data from the 47 Japanese prefectures are shown Tables 1 and 2.

Table 1. Dependent Variables Data: Medicine Costs (1 USD cent $=1 \mathrm{JPY})(\mathrm{N}=47)$

\begin{tabular}{lcccc}
\hline Dependent variables & Mean & Maximum & Minimum & Standard deviation \\
\hline Total medicine & 293.85 & 337.06 & 253.07 & 17.93 \\
Internal medicine & 243.05 & 277.65 & 208.19 & 16.07 \\
One-shot medicine & 1.96 & 3.32 & 1.15 & 0.57 \\
Injection medicine & 13.28 & 18.48 & 9.80 & 2.16 \\
Medical device & 0.73 & 1.44 & 0.37 & 0.25 \\
Brand-name medicine & 247.30 & 292.81 & 208.73 & 18.41 \\
Generic medicine & 46.55 & 54.18 & 40.59 & 2.98 \\
Technical Fee & 97.16 & 118.72 & 83.65 & 7.84 \\
Prescribed number of medicines & 2.89 & 3.14 & 2.62 & 0.13 \\
\hline
\end{tabular}

\subsection{Independent Variables and Weight}

\subsubsection{Expansion Rate (\%)}

The expansion rate refers to the number of separation system upgrades in Japan's administrative divisions, the prefectures. The data for fiscal year 2016 were obtained from JPA (2016).

3.2.2 Generic Medicine Replacement Ratio (\%)

These data were taken from the JMHLW website, being based on the trends in 2016 regarding the composition of medical expenses (for computation processing) (JMHLW, 2016). From these data, for each prefecture, the rate of generic medicines replaced by brand name ones (hereafter, generic medicine replacement ratio) was calculated. These data are precise, as they are based on universal healthcare and medical insurance data.

\subsubsection{Proportion of the Elderly}

Elderly persons were defined as those aged 75 or older. We obtained data on this group of individuals (hereafter, proportion of elderly) from the JSB (2016) website. The proportion of elderly in each prefecture is based on city and district population data captured by the JSB during the national census.

\subsubsection{Number of Doctors per 100000 Individuals}

These data were taken from the JMHLW website, being based on data from 2014 regarding the number of doctors in each prefecture. These data are collected every two years, making the 2014 the latest available.

Table 2. Independent Variables $(\mathrm{N}=47)$

\begin{tabular}{llccc}
\hline $\begin{array}{l}\text { Independent } \\
\text { variables }\end{array}$ & $\begin{array}{c}\text { Expansion } \\
\text { rate }\end{array}$ & $\begin{array}{c}\text { Generic medicine replacement } \\
\text { ratio }\end{array}$ & $\begin{array}{c}\text { Proportion of } \\
\text { elderly }\end{array}$ & $\begin{array}{c}\text { Number of doctors per } 100000 \\
\text { individuals }\end{array}$ \\
\hline Mean & 70.39 & 69.56 & 14.60 & 237.44 \\
Maximum & 86.90 & 79.90 & 18.80 & 307.90 \\
Minimum & 49.40 & 59.10 & 10.40 & 152.80 \\
Standard deviation & 8.77 & 3.67 & 1.95 & 38.61 \\
\hline
\end{tabular}




\subsection{Data Weights}

Here, data weight refers to the number of prescriptions reported as per the separation system upgrades among Japan's administrative divisions. The data for fiscal year 2016 were obtained from JPA (2016).

Table 3. Weight Data $(\mathrm{N}=47)$

\begin{tabular}{lc}
\hline Weight & Number of prescription sheets per prefecture \\
\hline Mean & 16529445 \\
Maximum & 95797235 \\
Minimum & 11239956 \\
Standard deviation & 17623019 \\
\hline
\end{tabular}

\subsection{Data Analysis}

We analyzed the daily costs of the eight items as dependent variables and performed multiple linear regression analysis by WLS with the number of prescription sheets in each prefecture. The weighted multiple regression analysis used the daily cost per prescription of total, internal, one-shot, external, and injection medicines, and medical devices as the dependent variable. Additionally, the expansion rate, generic medicine replacement ratio, proportion of elderly, and number of doctors per 100000 individuals were used as independent variables. All statistical analyses were performed using RStudio and R Commander.

\section{Results}

\subsection{Total Medicine Costs, Internal Medicine Costs and One-Shot Medicine Costs}

In the weighted multiple regression analysis, when the objective variable was daily total medicine cost, the $95 \%$ confidence intervals of the partial regression coefficients of the expansion rate ("separation ratio") and generic medicine replacement rate ("GE ratio") were negative. On the other hand, the number of doctors per 100000 individuals in the population ("Dr. number/100 000") was always positive. No trend was seen for the proportion of elderly ("75 years or over ratio"). Multiple regression formula: $\mathrm{Y}_{1}=0.0977 \mathrm{X}_{1}-1.5518 \mathrm{X}_{2}-1.0959 \mathrm{X}_{3}+0.6654 \mathrm{X}_{4}$ + 446.9369. Multiple R-squared: 0.7564

For daily internal medicine costs, the $95 \%$ confidence intervals of the partial regression coefficients of the separation and GE ratios were negative. On the other hand, no trends were seen for either the 75 years or over ratio or Dr. number $/ 100$ 000. Multiple regression formula: $\mathrm{Y}_{2}=0.0654 \mathrm{X}_{1}-1.4125 \mathrm{X}_{2}-0.9072 \mathrm{X}_{3}+1.5638 \mathrm{X}_{4}+$ 367.1454. Multiple R-squared: 0.5886

For daily one-shot medicine costs, the $95 \%$ confidence interval of the partial regression coefficient for the separation ratio was negative. On the other hand, no trends were seen for the GE, 75 years or over, or Dr. number $/ 100$ 000. Multiple regression formula: $\mathrm{Y}_{3}=-0.0003 \mathrm{X}_{1}-0.0298 \mathrm{X}_{2}-0.0443 \mathrm{X}_{3}+0.0056 \mathrm{X}_{4}+7.2075$. Multiple R-squared: 0.4142

Table 4. Results: Total Medicine Costs ( $\left.\mathrm{Y}_{1}\right)$, Internal Medicine Costs ( $\left.\mathrm{Y}_{2}\right)$ and One-off Medicine Costs ( $\left.\mathrm{Y}_{3}\right)$

\begin{tabular}{lrrr}
\hline Coefficient & Estimate & $95 \%$ lower limit & $95 \%$ upper limit \\
\hline Total Medicine Costs $\left(\mathrm{Y}_{1}\right)$ & & & 533.2479 \\
Intercept & 446.9396 & 360.5990 & 0.1777 \\
Dr. number/100 000 $\left(\mathrm{X}_{1}\right)$ & 0.0977 & 0.0177 & -0.4091 \\
GE ratio (\%) $\left(\mathrm{X}_{2}\right)$ & -1.5518 & -2.6945 & -0.6857 \\
Separation ratio $(\%)\left(\mathrm{X}_{3}\right)$ & -1.0959 & -1.5061 & 2.3850 \\
75 years or over ratio $(\%)\left(\mathrm{X}_{4}\right)$ & 0.6654 & -1.0542 & 445.9420 \\
\hline Internal Medicine Costs $\left(\mathrm{Y}_{2}\right)$ & & & 0.1318 \\
Intercept & 367.1454 & 288.3667 & -0.3698 \\
Dr. number/100 000 $\left(\mathrm{X}_{1}\right)$ & 0.0654 & -0.0076 & -2.4551 \\
GE ratio $(\%)\left(\mathrm{X}_{2}\right)$ & -1.4125 & & \\
\hline
\end{tabular}




\begin{tabular}{lccc}
\hline Separation ratio $(\%)\left(\mathrm{X}_{3}\right)$ & -0.9072 & -1.2816 & -0.5329 \\
75 years or over ratio $(\%)\left(\mathrm{X}_{4}\right)$ & 1.5638 & -0.0052 & 3.1329 \\
\hline One-off Medicine Costs $\left(\mathrm{Y}_{3}\right)$ & 7.2075 & 3.4189 & 10.9961 \\
Intercept & -0.0003 & -0.0038 & 0.0032 \\
Dr. number/100 000 $\left(\mathrm{X}_{1}\right)$ & -0.0298 & -0.0799 & 0.0204 \\
GE ratio (\%) $\left(\mathrm{X}_{2}\right)$ & -0.0443 & -0.0623 & -0.0263 \\
Separation ratio $(\%)\left(\mathrm{X}_{3}\right)$ & 0.0056 & -0.0699 & 0.0810 \\
75 years or over ratio $(\%)\left(\mathrm{X}_{4}\right)$ & & & \\
\hline
\end{tabular}

\subsection{External Medicine Costs, Injection Medicine Costs and Medical Device Costs}

For daily internal medicine costs, the $95 \%$ confidence interval of the partial regression coefficient for the 75 years or over ratio was negative. On the other hand, Dr. number/100 000 was positive. No trend was seen for the GE or separation ratios. Multiple regression formula: $\mathrm{Y}_{4}=0.0214 \mathrm{X}_{1}-0.1239 \mathrm{X}_{2}+0.0275 \mathrm{X}_{3}-0.6227 \mathrm{X}_{4}+46.5274$. Multiple R-squared: 0.6310 .

For daily injection medicine costs, the $95 \%$ confidence intervals of the partial regression coefficients for the separation ratio and of the 75 years or over ratio was negative. On the other hand, the Dr. number/100 000 was positive. No trend was seen for the GE ratio. Multiple regression formula: $\mathrm{Y}_{5}=0.0112 \mathrm{X}_{1}+0.0104 \mathrm{X}_{2}-0.1718 \mathrm{X}_{3}$ 0.2814X $\mathrm{X}_{4}+26.0759$. Multiple R-squared: 0.5483.

For daily medical device costs, the $95 \%$ confidence interval of the partial regression coefficient for the separation ratio was negative. On the other hand, no trends were seen for Dr. number/100 000, GE ratio, or 75 years or over ratio. Multiple regression formula: $\mathrm{Y}_{6}=0.0007 \mathrm{X}_{1}+0.0051 \mathrm{X}_{2}-0.0091 \mathrm{X}_{3}+0.0011 \mathrm{X}_{4}+0.8123$. Multiple R-squared: 0.1987

Table 5. Results: External Medicine Costs $\left(\mathrm{Y}_{4}\right)$, Injection Medicine Costs $\left(\mathrm{Y}_{5}\right)$ and Medical Device Costs $\left(\mathrm{Y}_{6}\right)$

\begin{tabular}{llll}
\hline Coefficient & Estimate & $95 \%$ lower limit & $95 \%$ upper limit \\
\hline External Medicine Costs $\left(\mathrm{Y}_{4}\right)$ & & & \\
Intercept & 46.5274 & 35.2654 & 57.7894 \\
Dr. number/100 000 $\left(\mathrm{X}_{1}\right)$ & 0.0214 & 0.0109 & 0.0318 \\
GE ratio $(\%)\left(\mathrm{X}_{2}\right)$ & -0.1239 & -0.2729 & 0.0252 \\
Separation ratio (\%) $\left(\mathrm{X}_{3}\right)$ & 0.0275 & -0.0260 & 0.0810 \\
75 years or over ratio $(\%)\left(\mathrm{X}_{4}\right)$ & -0.6227 & -0.8470 & -0.3984 \\
\hline Injection Medicine Costs $\left(\mathrm{Y}_{5}\right)$ & & & \\
Intercept & 26.0759 & 14.2151 & 37.9368 \\
Dr. number/100,000 $\left(\mathrm{X}_{1}\right)$ & 0.0112 & 0.0002 & 0.0222 \\
GE ratio (\%) $\left(\mathrm{X}_{2}\right)$ & 0.0104 & -0.1429 & 0.1710 \\
Separation ratio $(\%)\left(\mathrm{X}_{3}\right)$ & -0.1718 & -0.2281 & -0.1154 \\
75 years or over ratio $(\%)\left(\mathrm{X}_{4}\right)$ & -0.2814 & -0.5176 & -0.0452 \\
\hline Medical Device Costs $\left(\mathrm{Y}_{6}\right)$ & & & \\
Intercept & 0.8123 & -0.5674 & 2.1920 \\
Dr. number $/ 100000\left(\mathrm{X}_{1}\right)$ & 0.0007 & -0.0006 & 0.0020 \\
GE ratio $(\%)\left(\mathrm{X}_{2}\right)$ & 0.0051 & -0.0131 & 0.0234 \\
Separation ratio $(\%)\left(\mathrm{X}_{3}\right)$ & -0.0091 & -0.0157 & -0.0026 \\
75 years or over ratio $(\%)\left(\mathrm{X}_{4}\right)$ & 0.0011 & -0.0264 & 0.0286 \\
\hline
\end{tabular}




\subsection{Brand-Name Medicine Costs and Generic Medicine Costs}

For daily brand-name medicine costs, the $95 \%$ confidence intervals of the partial regression coefficients for the separation and GE ratios were negative. On the other hand, the one for Dr. number/100 000 was positive, but no trends were seen for Dr. number $/ 100000$ or the 75 years or over ratio. Multiple regression formula: $\mathrm{Y}_{7}=0.0932 \mathrm{X}_{1}$ $-2.2385 \mathrm{X}_{2}-1.0147 \mathrm{X}_{3}+0.1245 \mathrm{X}_{4}+451.0792$. Multiple R-squared: 0.7020 .

For daily generic medicine costs, the $95 \%$ confidence interval of the partial regression coefficient for the separation ratio was negative. On the other hand, those for the GE and 75 years or over ratios were positive. No trends were seen for Dr. number 100000 . Multiple regression formula: $\mathrm{Y}_{8}=0.0044 \mathrm{X}_{1}+0.6863 \mathrm{X}_{2}-0.08117 \mathrm{X}_{3}+$ $0.5411 \mathrm{X}_{4}$ - 4.1244. Multiple R-squared: 0.7564.

Table 6. Results: Brand-Name $\left(\mathrm{Y}_{7}\right)$ and Generic Medicine Costs $\left(\mathrm{Y}_{8}\right)$

\begin{tabular}{llll}
\hline Coefficient & Estimate & $95 \%$ lower limit & $95 \%$ upper limit \\
\hline Brand-Name Medicine Costs $\left(\mathrm{Y}_{7}\right)$ & & & \\
Intercept & 451.0792 & 373.2121 & 528.9462 \\
Dr. number/100 $000\left(\mathrm{X}_{1}\right)$ & 0.0932 & 0.0211 & 0.1653 \\
GE ratio $(\%)\left(\mathrm{X}_{2}\right)$ & -2.2385 & -3.2690 & -1.2079 \\
Separation ratio $(\%)\left(\mathrm{X}_{3}\right)$ & -1.0147 & -1.3847 & -0.6447 \\
75 years or over ratio $(\%)\left(\mathrm{X}_{4}\right)$ & 0.1245 & -1.4264 & 1.6753 \\
\hline Generic Medicine Costs $\left(\mathrm{Y}_{8}\right)$ & & & 8.8366 \\
Intercept & -4.1244 & -17.0854 & 0.0164 \\
Dr. number/100 000 $\left(\mathrm{X}_{1}\right)$ & 0.0044 & -0.0076 & 0.8579 \\
GE ratio $(\%)\left(\mathrm{X}_{2}\right)$ & 0.6863 & 0.5148 & -0.0195 \\
Separation ratio $(\%)\left(\mathrm{X}_{3}\right)$ & -0.0811 & -0.1427 & 0.7992 \\
75 years or over ratio $(\%)\left(\mathrm{X}_{4}\right)$ & 0.5411 & 0.2829 & \\
\hline
\end{tabular}

\subsection{Number of Prescribed Medicines and Technical Fee}

For the number of prescribed medicines, the $95 \%$ confidence interval of the partial regression coefficient for the separation ratio was negative. On the other hand, the one for the 75 years or over ratio was positive. No trends were seen for Dr. number $/ 100000$ or the GE ratio. Multiple regression formula: $\mathrm{Y}_{9}=0.0007 \mathrm{X}_{1}+0.0040 \mathrm{X}_{2}-0.0044 \mathrm{X}_{3}+$ $0.0374 \mathrm{X}_{4}+2.2170$. Multiple R-squared: 0.4883 .

For the technical fee, the $95 \%$ confidence interval of the partial regression coefficient for the separation ratio was negative. On the other hand, the one for Dr. number/100 000 was positive. No trends were seen for the GE or 75 or over ratio. Multiple regression formula: $\mathrm{Y}_{10}=0.0834 \mathrm{X}_{1}+0.4016 \mathrm{X}_{2}-0.3084 \mathrm{X}_{3}-0.5052 \mathrm{X}_{4}+79.4458$. Multiple R-squared: 0.3529 . 
Table 7. Results: Number of Prescribed Medicines $\left(\mathrm{Y}_{9}\right)$ and Technical Fee $\left(\mathrm{Y}_{10}\right)$

\begin{tabular}{llll}
\hline Coefficient & Estimate & $95 \%$ lower limit & $95 \%$ upper \\
\hline limitNumber of Prescribed Medicines $\left(\mathrm{Y}_{9}\right)$ & & & \\
Intercept & 2.2170 & 1.3841 & 3.0499 \\
$\quad$ Dr. number/100 000 $\left(\mathrm{X}_{1}\right)$ & 0.0007 & -0.0001 & 0.0015 \\
$\quad$ GE ratio $(\%)\left(\mathrm{X}_{2}\right)$ & 0.0040 & -0.0070 & 0.0150 \\
Separation ratio $(\%)\left(\mathrm{X}_{3}\right)$ & -0.0044 & -0.0084 & -0.0005 \\
$\quad$ 75 years or over ratio $(\%)\left(\mathrm{X}_{4}\right)$ & 0.0374 & 0.0208 & 0.0539 \\
\hline Technical Fee $\left(\mathrm{Y}_{10}\right)$ & & & \\
Intercept & 79.4458 & 29.3213 & 129.5702 \\
$\quad$ Dr. number/100,000 $\left(\mathrm{X}_{1}\right)$ & 0.0834 & 0.0370 & 0.1298 \\
$\quad$ GE ratio $(\%)\left(\mathrm{X}_{2}\right)$ & 0.4016 & -0.2618 & 1.0650 \\
$\quad$ Separation ratio $(\%)\left(\mathrm{X}_{3}\right)$ & -0.3084 & -0.5466 & -0.0703 \\
75 years or over ratio $(\%)\left(\mathrm{X}_{4}\right)$ & -0.5052 & -1.5035 & 0.4932 \\
\hline
\end{tabular}

\section{Discussion}

\subsection{Separation System}

The partial regression coefficient of the separation ratio for total medication costs is -1.0959 . Therefore, a $1 \%$ increase in the separation system reduces each prescription by USD -1.0959 cents. As the number of prescription sheets in Japan is around 800000000 (JPA, 2016), it is presumed that a 1\% increase in the separation system would yield a reduction of around USD 8767200 per day. Furthermore, as the average number of prescription days in Japan (JMHLW, 2016) is 23.1, cost would be reduced by USD 202522320 per prescription per year.

No significant partial trends were found between the expansion rate and external medicine, because the most popular medicines in this category on the Japanese market are light painkillers, allowing patients to make their own purchase and use decisions (Yokoi \& Tashiro, 2016).

\subsubsection{Brand-Name and Generic Medicine Costs}

The partial regression coefficient of the separation ratio for brand-name medicine costs is -1.0147 and -0.081 for generic medicine. Therefore, the highest reduction of the separation system is due to brand-name medicine costs. The reason is considered as follows: the ratio of generic medicine replacement ratio is continuously increasing, as the Japanese government promotes it politically. In other words, Japanese pharmaceutical companies are forced to promote brand-name medicines with no generic alternatives because of ensuring profit.

\subsubsection{Number of Prescribed Medicine}

As the partial regression coefficient is -0.0044 , the difference in the number of prescribed medicines between $0 \%$ and $100 \%$ of the expansion rate is 0.44 . As the average number of prescribed medicines is 2.83 (JMHLW, 2016), the effect is not negligible. This means the separation system is reducing excess prescribed medicines.

\subsubsection{Technical Fee}

The expansion rate of the separation system is negative and partially significant in relation with technical fees. This means the separation system is effective, not only for medicine costs but also technical fees. The expansion of the separation system is thus causing the market mechanism to function normally.

\subsection{Generic Medicine Ratio}

The use of generic medicines to reduce costs is a well-known practice. Numerous generic medicines are available, leading to a significant cost-reduction trend in terms of internal medicines. On the other hand, for external and injection medicines and medical devices, where few or no generic medicines are available, no such trend was observed. Although Japanese community pharmacies can legally claim technical fees for dispensing generic medicine over a certain amount, its influence was null.

\subsection{Number of Doctors per 100000 Individuals}

The daily costs of total, internal, external, and injection medicines had significant and partially positive 
relationships with Dr. number/100 000. This finding does not contradict those of previous studies, as a growth in Dr. number/100 000 has naturally led to an increase in total medical expenses. Furthermore, brand-name medicine costs also had a significant and partially positive relationship with Dr. number/100 000, while generic medicine costs had not as explained in 5.1.1. Although technical fees are charged by community pharmacies, they had a significant and partially negative relationship with Dr. number/100,000. It is presumed that increasing the number of doctors, more prescriptions and community pharmacies. Because more patients are able be medically examined, and prescribed medicines.

As a result, the technical fees of pharmacies tend to decrease because of the intense competition among them.

\subsection{Proportion of Elderly}

In any case, attention should be drawn to the increasing 75 years or over ratio and its role in increasing overall medicine costs. The increase in this ratio was proven not to increase medicine costs per prescription because the elderly tend to consult numerous medical institutions and receive several prescriptions.

On the other hand, generic medicine costs and number of prescribed medicines had a significant and partially positive relationship with the proportion of the elderly. This means doctors tend to prescribe well-used medicines such as generic ones and more medicines than for other patient categories because the elderly patients typically suffer from more diseases and take more medicines on average.

\subsection{Limitations}

Although we found the growth rate of the separation system to be significantly and negatively correlated with the expenses for daily medicines and medical devices per prescription, daily brand-name, and generic medicines, technical fee, and number of medicines. The possible reasons for these findings are hypothetical, and this study was unable to verify them. Consequently, we must investigate the actions and thoughts of patients, doctors, and pharmacists in future research.

\section{Conclusion}

We found that the daily costs of total, internal, one-shot, and injection medicines and medical devices had significant and partially negative relationships with the expansion rate. First, the separation system strongly influenced cost reduction in these areas. On the other hand, no significant partial trends were found between the expansion rate and external medicine.

The expansion rate of the separation system is negative and shows a partially significant relationship with brand-name and generic medicine costs, the number of prescribed medicines, and technical fees. The daily costs of total and internal, external, one-shot, and brand-name medicines had significant and partially negative relationships with the expansion rate. The daily costs of total, internal, external, and injection medicines had significant and partially positive relationships with Dr. number/100 000. Finally, generic medicine costs and number of prescribed medicines had a significant and partially positive relationship with the proportion of the elderly.

\section{Acknowledgments}

We would like to voice our appreciation to Dr. Takao Tashiro, a member of the Tashiro seminar and of the teaching staff at the Open University of Japan, and to Dr. Tadashi Suzuki for their advice. We received no financial support for this research and have no interests that could be construed as biasing the results of this work. We would like to thank Editage (www.editage.jp) for English language editing.

\section{Competing Interests Statement}

The authors declare no conflict of interests regarding the publication of this paper.

\section{References}

Akinbosoye, O. E., Taitel, M. S., Grana, J., Hill, J., \& Wade, R. L. (2016). Improving medication adherence and health care outcomes in a commercial population through a community pharmacy. Population Health Management, 19(6), 454-461. https://doi.org/10.1089/pop.2015.0176

Elliott, R. A., Putman, K., Davis, J., \& Annemans, L. (2014). A review of the methodological challenges in assessing the cost effectiveness of pharmacist interventions. Pharmacoeconomics, 32(12), 1185-1199. https://doi.org/10.1007/s40273-014-0197-z

Japan Pharmaceutical Association. (2016). Separation of pharmacy and clinic progress rate, data for 2016. Retrieved February 14, 2018, from http://www.nichiyaku.or.jp/contents/bungyo/h28/s/28sukei.pdf 
Japanese Statistics Bureau of the Ministry of Internal Affairs and Communications. Summary of survey results of population data for 2016. Retrieved February 14, 2018, from http://www.stat.go.jp/data/jinsui/2016np/index.htm\#a05k28-a

Ministry of Health, Labour and Welfare. (2016). Medical expenses of dispensing medicine, data for 2016. MHLW, Insurance Bureau Security Research Division. Retrieved February 14, 2018, from http://www.mhlw.go.jp/topics/medias/c-med/2017/03/pdf/data.pdf

Ministry of Health, Labour and Welfare. Summary of doctor, dentist, pharmacist survey statistical sable, data for 2014. MHLW, Insurance Bureau Security Research Division. Retrieved February 14, 2018, from http://www.mhlw.go.jp/toukei/saikin/hw/ishi/14/dl/toukeihyo.pdf

Touchette, D. R., Doloresco, F., Suda, K. J., Perez, A., Turner, S., Jalundhwala, Y., ... \& Hoffman, J. M. (2014). Economic evaluations of clinical pharmacy services: 2006-2010 Pharmacotherapy, 34(8), 771-793. https://doi.org/10.1002/phar.1414

Yokoi, M., \& Tashiro, T. (2014). Influence of separation of prescription and dispensation of medicine on its cost in Japanese prefectures. Global Journal of Health Science, 6(4), 57-62. https://doi.org/10.5539/gjhs.v6n4p57

Yokoi, M., \& Tashiro, T. (2016). Prescription, dispensation, and generic medicine replacement ratios: Influence on Japanese medicine costs. Global Journal of Health Science, 8(1), 29-35. https://doi.org/10.5539/gjhs.v8n1p29

\section{Copyrights}

Copyright for this article is retained by the author(s), with first publication rights granted to the journal.

This is an open-access article distributed under the terms and conditions of the Creative Commons Attribution license (http://creativecommons.org/licenses/by/4.0/). 